JURNAL JENDELA ILMU

Vol.1, No. 1, Juni 2020, hlm. 23-28

\title{
ANALISIS PENGAWASAN PENGGUNAAN DANA BANTUAN OPERASIONAL SEKOLAH DI SD YPK EBENHAEZER LIMALAS KABUPATEN RAJA AMPAT
}

\author{
Joseph E Lopulalan \\ Universitas Victory Sorong \\ Email: josephlopulalan@gmail.com
}

\begin{abstract}
Abstrak
Berdasarkan hasil pengamatan penelitian pada SD YPK EBENHAEZER Limalas Distrik Misool timur kabupaten Raja Ampat, di peroleh bahwa penggunaan Dana Bantuan Operasional Sekolah (BOS) di sekolah ini sudah sesuai dengan apa yang di tetapkan oleh pemerintah menurut peraturan Menteri Pendidikan No 80 tahun 2016 tentang petunjuk teknis penggunaan dan pertanggungjawaban Dana BOS dimana para pengelolah dana BOS yakni kepala sekolah dan bendahara sekolah diwajibkan mengikuti pelatihan dan penyusunan Dana Bantuan Operasional Sekolah dari pemerintah daerah dalam hal ini Dinas Pendidikan Kabupaten Raja Ampat. Guna memperoleh informasih bagi penelitian ini, maka sampel ditarik berdasarkan tujuan dan pertimbangan kepentingan penelitian (Purpossive Sampling) sehingga dapat mewakili setiap bagian sampel penelitian dimana perancanaan pelaksanaan dan pengawasan pengelolaan Dana Bantuan Operasional Sekolah. Penelitian ini juga melibakan perangkat sekolah termasuk kepala sekolah, staf dewan guru, bendahara sekolah, komite sekolah dan warga masyarakat/orang tua wali murid SD YPK EBENHAEZER Limalas. Saran-saran yang dapat peneliti kemukakan berupa saran praktis dengan lebih memperhatikan hal-hal yang penting dalam pengelolahan dan pertanggugungjawaban Dana Bantuan Operasional Sekolah (BOS). Dan saran Akademis dengan memperluas wawasan ilmu pengetahuan dan mengembangkan data serta informasi mengenai pentingnya Penggunaan Dana Bantuan Operasional Sekolah.
\end{abstract}

Kata kunci: Bantuan Operasional Sekolah, Pengelolaan BOS.

\section{MONITORING OF THE USE OF SCHOOL OPERATIONAL ASSISTANCE FUND IN SD YPK EBENHAEZER LIMALAS REGENCY OF RAJA AMPAT}

\begin{abstract}
Based on the results of observations at the SD YPK EBENHAEZER Limalas district of East Misool, Raja Ampat Regency, it was found that the use of the School Operational Assistance Fund (BOS) in this school was in accordance with what was set by the government according to Minister of Education regulation No. 80 of 2016 concerning technical guidelines the use and accountability of the BOS Fund where BOS funds managers, school principals and treasurers are required to attend training and preparation of the School Operational Assistance Fund from the local government in this case the Raja Ampat District Education Office. In order to obtain information for this research, the sample was drawn based on Purpossive Sampling so that it could represent each part of the research sample where the planning of the implementation and supervision of the management of the School Operational Assistance Fund. This research also included school equipment including the principal, board staff of teachers, school treasurers, school committees and community members / parents of elementary school students YPK EBENHAEZER Limalas. Suggestions that can be put forward in the form of practical advice by paying more attention to the important things in the management and accountability of the School Operational Assistance Fund (BOS). And Academic advice by expanding knowledge and developing data and information about the importance of the Use of School Operational Assistance Funds.
\end{abstract}

Keywords: System School Operational Assistance, BOS Management.

\section{PENDAHULUAN}

Pendidikan merupakan salah satu pilar penyangga pembangunan masyarakat. Oleh karena itu, negara sebagai penjamin kehidupan masyarakat harus mampu menyelenggarakan pendidikan agar taraf hidup masyarakatnya semakin baik. Dalam Undang-Undang Nomor 20 Tahun 2003 tentang Sistem Pendidikan Nasional, disebutkan bahwa setiap warga negara berusia $7-15$ tahun wajib 
mengikuti pendidikan dasar. Sedangkan Pasal 34 Ayat 2 Undang-Undang Dasar Negara Republik Indonesia menyebutkan bahwa Pemerintah dan Pemerintah Daerah menjamin terselenggaranya wajib belajar minimal pada jenjang pendidikan dasar tanpa memungut biaya, dalam Ayat 3 juga disebutkan bahwa wajib belajar merupakan tanggung jawab negara yang diselenggarakan oleh lembaga pendidikan Pemerintah, Pemerintah Daerah, dan masyarakat ${ }^{1}$. Untuk mewujudkan amanah Undang-Undang tersebut, maka pemerintah wajib menyelenggarakan layanan pendidikan bagi seluruh peserta didik pada tingkat pendidikan dasar yaitu SD dan SMP serta satuan pendidikan lain yang sederajat. Sebagai upaya untuk melaksanakan kewajiban menyelenggarakan pendidikan dasar tanpa biaya, Pemerintah menciptakan program Bantuan Operasional Sekolah (BOS). Berawal pada tahun 2005, BOS merupakan bentuk kompensasi kenaikan bahan bakar minyak di bidang pendidikan yang awalnya bertujuan mempercepat pencapaian program Wajib Belajar (Wajar) 9 tahun. Kemudian pada tahun 2009, Pemerintah melakukan perubahan tujuan, pendekatan dan orientasi program BOS tersebut, sehingga program BOS tidak hanya bertujuan menopang program Wajar dengan cara mempertahankan jumlah peserta didik saja, namun juga harus berkontribusi dalam peningkatan mutu pendidikan dasar. Selain itu, kenaikan jumlah dana BOS yang signifikan mulai tahun 2009 diharapkan akan menjadikan BOS sebagai pilar utama mewujudkan pendidikan dasar tanpa dipungut biaya.

1. Pengelolaan BOS dipandu oleh ketentuanketentuan teknis yang harus dipahami dan dijalankan oleh segenap unsur yang terlibat, yaitu: Tim Manajemen BOS Pusat, Tim Manajemen BOS Provinsi, Tim Manajemen BOS Kabupaten/Kota, dan sekolah. Kesalahan pemahaman oleh pengelola dapat menimbulkan hambatan dalam pelaksanaan program BOS.

2. Sekolah menempati posisi ujung tombak pencapaian tujuan BOS, karena sekolah merupakan instansi yang terkait langsung dengan pengelolaan dana. Menurut ketentuan, dana BOS dikelola oleh kepala sekolah dan guru atau tenaga administrasi yang ditunjuk sebagi bendahara BOS. Sekolah boleh menggunakan dana BOS untuk beberapa jenis pengeluaran sesuai program dan berdasarkan Rencana Anggaran Pendapatan Belanja Sekolah (RAPBS) yang disusun oleh sekolah dan Komite Sekolah.

3. Dalam pengelolaannya di tingkat sekolah terkhusus sekolah-sekolah di daerah, BOS

\footnotetext{
1 Undang-Undang Nomor 20 Tahun 2003 tentang Sistem Pendidikan Nasional.
}

menjadi masalah yang cukup serius. Hal ini terindikasi oleh hasil pemeriksaan Badan Pemeriksa Keuangan (BPK) pada tahun anggaran 2017 dan semester I 2018 pada 3.237 sekolah sampel di 33 provinsi, ditemukan nilai penyimpangan dana BOS lebih kurang Rp 28 miliar. Penyimpangan itu terjadi di 2.054 atau $63,5 \%$ dari total sampel sekolah yang diperiksa. Pada periode 2004 - 2009, kejaksaan dan kepolisian seluruh Indonesia berhasil menindak 33 kasus korupsi terkait dengan dana operasional sekolah termasuk dana BOS. Celah yang memungkinkan terjadinya penyimpangan pengelolaan dana BOS ini adalah minimnya tenaga pengelola BOS yang berkompeten dan memiliki pengetahuan mengenai akuntansi ataupun perpajakan secara spesifik di tingkat sekolah. Selain itu seperti terlansir dalam media massa, hanya sebagian kecil sekolah yang telah selesai menyusun RAPBS sebelum BOS dikucurkan (Media Indonesia) $^{2}$. Padahal seharusnya sebelum dana BOS cair, sekolah sudah harus memiliki RAPBS yang menjadi dasar anggaran untuk pelaksanaan program-program sekolah. Kejadian seperti ini memungkinkan terjadinya penyimpangan berupa mark up RAPBS sehingga semua dana BOS yang diterima teralokasikan tetapi untuk tujuan-tujuan yang tidak terlalu penting atau melenceng dari tujuan program ini yaitu menunjang mutu pendidikan dasar.

4. Pengawasan pengelolaan dana BOS tidak sepenuhnya menjadi tanggung jawab pemerintah, tapi juga menjadi tanggung jawab masyarakat sebagai pengawal program pemerintah termasuk program BOS. Penyelewengan yang terjadi secara tidak langsung juga merupakan akibat dari minimnya partisipasi dan transparansi publik. Pengelolaan BOS selama ini terlalu didominasi oleh kepala sekolah dan bendahara BOS. Peran warga sekolah dan masyarakat kurang diperhatikan dalam pengawasan pengelolaan BOS. Padahal dengan pengendalian dari publik masalah penyelewengan dapat diminimalisir. Oleh karena itu, Komisi Informasi Pusat (KIP) memutuskan bahwa surat pertanggungjawaban BOS adalah dokumen publik yang bersifat terbuka, kuitansi maupun SPJ dapat diakses masyarakat. Dengan keputusan ini diharapkan masyarakat dapat ikut mengawasi penyelenggaraan dana BOS agar berjalan lebih baik dan minim penyimpangan.

5. Program BOS diharapkan dapat dikelola sesuai dengan asas Manajemen Berbasis Sekolah

2

http://www.mediaindonesia.com/read/2018/15/06 /menyoal-penyimpangan-dana-bos 
(MBS), yang secara umum bertujuan untuk memberdayakan sekolah melalui pemberian kewenangan (otonomi), pemberian fleksibilitas yang lebih besar untuk mengelola sumber daya sekolah, dan mendorong partisipasi warga sekolah dan masyarakat untuk meningkatkan mutu pendidikan di sekolah. Oleh karena itu dalam pengelolaan dana BOS sekolah dituntut untuk mengembangkan pengelolaan dana secara profesional, transparan dan akuntabel. Sekolah juga dituntut untuk meningkatkan akses, mutu dan manajemen sekolah. Penyusunan rencana untuk jangka menengah dan jangka pendek juga harus dilaksanakan oleh sekolah, dengan mendapat pertimbangan dari Komite Sekolah dan persetujuan Dinas Pendidikan Kabupaten/Kota atau yayasan bila merupakan sekolah swasta.

6. Adapun penggunaan dana BOS di Kabupaten Raja Ampat tidak jauh berbeda dengan apa yang dipaparkan oleh media masa di awal bagian ini, untuk itu maka SD YPK Ebenhazer Limalas dijadikan sampel observasi guna mengamati fenomena ini. Melalui observasi awal penulis pada SD YPK Ebenhazer Limalas penulis mendapatkan kondisi umum penggunaan dana BOS namun terindikasi kurangnya pelibatan Komite Sekolah dalam perencanaan penggunaan dana BOS yang seharusnya terancang dalam RAPBS. Selain itu, orang tua siswa sebagai bagian dari warga sekolah yang juga adalah warga masyarakat tidak mendapatkan kejelasan akan penggunaan dana BOS dari pihak sekolah sebagai pengelola bantuan pemerintah kepada masyarakat melalui lembaga pendidikan ini. Dari hasil observasi awal ini penulis kemudian membuat kesimpulan awal bahwa baik pihak sekolah sebagai pengelola dana BOS, Komite Sekolah maupun warga masyarakat belum memahami benar tujuan dari BOS, bagaimana pengelolaannya serta bagaimana pengawasan terhadap pelaksanaannya.

7. Mengamati fenomena pengelolaan BOS yang selama ini lebih terfokus pada sudut pandang manajerial dan akuntansi, penulis tertarik untuk menelitinya dari ranah administrasi negara dengan mendudukkan dasar penelitian ini pada ranah fungsi pengawasan masyarakat terhadap penyelenggaraan program BOS.

\section{METODE}

Penelitian ini dilakukan dengan pendekatan deskriptif kualitatif. Penelitian deskriptif bertujuan untuk mendeskripsikan atau menggambarkan atau melukiskan apa-apa yang saat ini berlaku di dalamnya. Yang dimaksud di dalamnya terdapat upaya mendeskipsikan, mencatat, menganalisa dan menginterpretasikan kondisi yang berlaku sekarang ini, terjadi atau ada (Mardalis, 1999:26).

Dengan demikian maka peneliti harus berusaha memperoleh informasi-informasi mengenai keadaan saat ini dengan mengaitkannya dengan variabel-variabel yang diteliti melalui pemberian kesempatan yang seluas-luasnya kepada informan atau responden untuk menyampaikan pikiran, pandangan, perasaan, pengetahuan dan pengalamannya yang berhubungan dengan masalah dan tujuan penelitian.

\section{HASIL DAN PEMBAHASAN}

Data hasil penelitian ini terhimpun oleh peneliti melalui observasi langsung terhadap pengelolaan dana BOS di SD YPK Ebenhaezer Limalas dan wawancara dengan para informan yaitu Kepala SD YPK Ebenhaezer Limalas, Ketua Komite SD YPK Ebenhaezer Limalas, Bendahara BOS, satu orang staf guru dan dua orang tua/wali murid. Hasil wawancara yang diperoleh peneliti dianalisa dan diuji timbal balik antara hasil wawancara para informan untuk mendapatkan data terakurat sesuai dengan masalah penelitian.

Berkenaan dengan apa yang diperoleh peneliti dari observasi dan wawancara secara mendalam ini, secara umum peneliti menemukan bahwa Dana BOS sangat diperlukan dan sangat penting bagi keberlangsungan sekolah dan mutu pendidikan yang dilaksanakan oleh SD YPK Ebenhaezer Limalas, mengingat sekolah ini merupakan sekolah yayasan yang membutuhkan donasidonasi keuangan untuk menunjang keberlangsungannya. Terlepas dari donasi dari pihak yayasan, sebagai suatu penyelenggara pendidikan dasar, dukungan pemerintah berupa Dana BOS ini dirasakan sangat membantu terlaksananya penyelenggaraan pendidikan yang bermutu yang pada kenyataannya belum dengan baik dapat dihadirkan pihak sekolah tanpa donasi dari pihak lain selain pihak yayasan. Mengenai hal ini, peneliti dalam wawancara dengan Kepala Sekolah SD YPK Ebenhaezer Limalas, Bapak Robert Ayal S.pd beliau bertutur "Sebagai sekolah yayasan, kami didanai sebagian oleh Yayasan Pendidikan Kristen, namun secara operasional kami berada dalam koordinasi dengan Dinas Pendidikan, itu berarti kami juga dijamin oleh pemerintah, meskipun kami ini sekolah swasta. Sebagai penyelenggara pendidikan dasar, kami perlu mendapat perhatian serius, itu terbukti dengan berbagai pendampingan yang dilakukan Dinas, termasuk terdaftarnya kami sebagai salah satu sekolah penerima BOS. Tentang BOS ini kami sangat perlukan, karena walaupun ini sekolah 
swasta, tetapi peserta didik kami ini merupakan masyarakat yang tergolong masyarakat desa, kami dari segi lokasi saja sulit mendapat penunjang pembelajaran seperti buku dan perpustakaan.

Pada tahun 2016 ini SD YPK Ebenhaezer Limalas sudah mendapat dana BOS sebanyak tiga kali masing-masing sebesar Rp. 102.400.000.00(seratus dua juta empat ratus ribu rupiah) Dana BOS ini di dapat setiap tiga bulan sesuai dengan jumlah murid di sekolah dikali permurid 800.000.00 (delapan ratus ribu rupiah)."

\section{Penetapan RAPBS pada SD YPK Ebenhaezer Limalas}

Pengelolaan operasional sekolah memiliki acuan yang ditetapkan oleh sekolah sesuai dengan kebutuhan penyelenggaraan proses belajar-mengajar dan administrasi ketatausahaan. Acuan ini berbeda pada tiap sekolah, pembedanya adalah karakteristik sosial budaya dan ekonomi yang dimiliki tiap sekolah. Untuk itu sekolah wajib menuangkannya secara legal untuk dipergunakan sebagai pemandu pelaksanaan dan penyelenggaraan pendidikan di sekolah dalam jangka waktu tertentu. Acuan ini dikenal dengan Rencana Anggaran Pendapatan dan Belanja Sekolah (RAPBS).

Penetapan RAPBS melibatkan segenap unsur sekolah, baik staf guru dan tata usaha sekolah yang dikepalai oleh Kepala Sekolah dan para stakeholder yaitu orang tua/wali murid dan murid. Dalam rangka terorganisirnya aspirasi orang-tua/wali murid dalam mendampingi dan mengawasi pelaksanaan pendidikan di sekolah dan menjadi wadah penyaluran aspirasi orang tua murid, maka terbentuklah Komite Sekolah. Maka penetapan RAPBS ini wajib melibatkan Komite Sekolah.

Peneliti menemukan bahwa di SD YPK Ebenhaezer Limalas juga melaksanakan penetapan RAPBS sebagaimana tergambar dalam hasil wawancara peneliti dengan Kepala SD YPK Ebenhaezer Limalas sebagai berikut:

"Tentu saja ada penetapan rencana setiap tahunnya, ini kami tetapkan bersama dengan komite sekolah dan orang tua dalam rapat kerja sekolah mengawali setiap tahun ajaran. Sekolah ini memang saya pimpin, setiap prosesnya dilakukan bersama staf guru dan tata usaha, tetapi apa yang kami lakukan ini diatur dalam rapat kerja sekolah dimana RAPBS ditetapkan, selanjutnya juga akan ada pertanggungjawaban pelaksanaan program yang ditetapkan pada rapat kerja sekolah ditahun berikutnya. Banyak masukan yang kami terima, dan banyak juga kritikan kami terima, semua untuk berlangsungnya sekolah ini kedepan."

Selanjutnya Ketua Komite Sekolah SD YPK Ebenhaezer Limalas Bapak Marten Falon juga memberikan keterangan tentang peran komite sekolah dalam rapat kerja sekolah yang bertugas untuk menetapkan RAPBS.

"Komite Sekolah harus bersuara dalam rapat kerja sekolah karena yang dididik di sekolah ini adalah anak-anak kita sendiri, kebanyakan orang tua hanya tau mengkritik apa yang dilakukan sekolah, tetapi tidak mau tau dengan suka-duka sekolah, lewat rapat kerja baik guru, baik orang tua/wali semua dapat memberikan sumbangsih pikir tentang apa yang baik dan perlu dilakukan dalam 1 tahun ajaran. Komite ini hanya perwakilan yang membawa suara orang tua, jadi orang tua harus tahu bahwa mereka punya hak dan kewajiban dalam menentukan mutu sekolah atau mutu pendidikan bagi anakanaknya."

Dari penjelasan yang di dapat dari informan di atas tergambar bahwa SD YPK Ebenhaezer Limalas telah menerapkan dimensi demokrasi dalam penyelenggaraan pendidikannya. Tergambar pula bahwa banyak keluhan yang lahir dalam bentuk kritikan yang sering disampaikan orang tua/wali setelah suatu kebijakan dan program sekolah dilaksanakan, namun terkadang ada juga orang tua/wali yang tidak memahami bahwa apa yang dilakukan itu sudah ditetapkan sebelumnya dalam rapat kerja sekolah dalam bentuk RAPBS yang disepakati bersama oleh pihak sekolah dan orang tua/wali diwakili oleh komite sekolah. Jadi apa yang dilakukan sekolah selama satu tahun ajaran sudah ditetapkan bersama, namun dilaksanakan oleh sekolah dengan Kepala Sekolah dan dewan guru sebagai eksekutor program sekolah untuk dilakukan bersama baik guru, murid dan orang tua/wali.

Tentang keterlibatan komite sekolah sebagai representasi dari seluruh orang tua/wali dalam penetapan RAPBS di SD YPK Ebenhaezer Limalas, yang berarti bahwa seluruh orang tua/wali murid tidak perlu menghadiri rapat kerja dimaksud namun apapun keputusan rapat kerja diberlakukan bagi sekolah seutuhnya termasuk murid dan orang tua/wali dan bagaimana cara mengsosialisasikannya kepada seluruh warga sekolah, maka untuk 
keperluan data ini, peneliti telah mewawancarai salah satu orang tua/wali murid SD YPK Ebenhaezer Limalas (Bpk. Ruben Leunufna) yang memberikan keterangan sebagai berikut:

"Kami tidak hadir dalam rapat untuk rancang program, tapi ada komite di sana yang mewakili orang tua murid, nanti kami dengar keputusannya dalam rapat komite, disitu baru kami hadir. Rapat komite ini tempat kami kasi masukan dan kritik, kekecewaan dan masalah yang kami hadapi sebagai orang tua murid, disini juga kami dapat alasan tentang hal-hal yang kami masalahkan, karena memang mereka sudah bahas dan rancangkan baru mereka buat, jadi ketika rapat ambil rapor itu sudah tidak banyak yang macam-macam lagi, jadi ambil rapor itu tra lamalama, yang bikin lama itu karena bicara tentang kebijakan yang tidak diatur sebelumnya karena mendadak harus buat."

RAPBS merupakan syarat pengucurannya, namun bukan berarti bahwa seluruh program sekolah harus didanai oleh Dana BOS, melainkan hanya program-program sekolah yang sesuai dengan aturan penggunaan dana BOS menurut Peraturan Menteri Pendidikan Nasional Nomor 80 Tahun 2016 tentang Juknis penggunaan dan pertanggungjawaban dana BOS. Berikut di bawah ini peneliti menguraikan hasil penetapan RAPBS SD YPK EBENHAEZER Limalas tahun anggaran 2016 setiap triwulan.

\section{PEMBAHASAN}

Bantuan Operasional Sekolah (BOS) sebagai suatu bentuk subsidi Bahan Bakar Minyak yang disalurkan dalam bentuk pembiayaan pendidikan yang menunjang dan meningkatkan mutu pendidikan dasar dan menengah di Indonesia dalam penerapannya di SD YPK Ebenhaezer Limalas, sebuah sekolah swasta yang menerima pengucuran dana BOS tahun 2016, beralamat di Jln Pendidikan Kampung Limalas, Distrik Misool Timur Kabupaten Raja Ampat Provinsi Papua Barat membuktikan bahwa program pemerintah ini telah mencapai pelosok tanah air.

Kepedulian pemerintah sebagai bentuk tanggung jawab mencerdaskan kehidupan bangsa ini kemudian harus diresponi juga dengan penuh tanggung jawab oleh setiap pihak yang mengelolanya, jika tidak demikian maka sasaran pelaksanaan kebijakan subsudial ini tidak akan menyentuh rakyat penerima manfaat sebagai sasaran utamanya. Bentuk renspon positif inilah yang diteliti secara mikro melalui penelitian ini.

Berdasarkan segenap himpunan data penelitian yang telah diperoleh dan dilaporkan pada bagian sebelumnya maka terlaksanalah analisa tentang pengelolaan dana BOS pada SD YPK Ebenhazer Limalas yang mendapatkan suatu kejelasan bahwa pengelolaan BOS telah berpayung hukum kuat berupa peraturan Menteri Pendidikan Nasional dalam koordinasi dengan Menteri Keuangan Negara dan Menteri Kesejahteraan Rakyat yang secara spesifik mengatur tentang tata cara pelaksanaan program Bantuan Masyarakat ini.

Di tingkat daerah, pemerintah merangkul seluruh sekolah negeri maupun swasta yang menyelenggarakan pendidikan dasar dan menengah di bawah koordinator Dinas Pendidikan Tingkat II sehingga seluruhnya berhak menerima BOS namun disyarati dengan ketentuan yang mengikat pengelolaannya.

Adapun syarat pengucuran BOS secara tertanggung jawab yang terpantau oleh Pemerintah Daerah adalah mengenai pemenuhan syarat utama pengucuran BOS bagi sekolah yang berhak berupa adanya RAPBS sebagai bentuk kebertanggungjawabaan sekolah dalam menjalankan Manajemen Berbasis Sekolah (MBS) dalam pengelolaan penyelenggaraan pendidikan.

Dilain pihak masyarakat sebagai sasaran program pemerintah ini yang tidak lain dalam maksud ini adalah murid/siswa dan orang tua/wali murid dalam skenario demokrtisasi bertindak sebagai pengawas penerapan program pemerintah ini. Pada Konteks SD YPK Ebenhaezer Limalas, fungsi pengawasan ini telah dijalankan secara representatif oleh Komite Sekolah sebagai wadah independen mitra sekolah yang berasal dari orang tua/wali murid sendiri yang turut terlibat secara aktif mulai dari proses penetapan RAPBS, sampai kepada pengawasannya secara non teknis. Secara teknis pengawasan melekat terhadap pengelolaan BOS di SD YPK Ebenhaezer Limalas berlaku secara merata seragam sesuai Peraturan Menteri Pendidikan Nasional Nomor 80 Tahun 2016 tentang Juknis penggunaan dan pertanggungjawaban dana BOS yakni berupa laporan pertanggungjawaban pengelolaan dana BOS oleh Pengelola BOS kepada Dinas Pendidikan Kabupaten Raja Ampat.

Sebagai hasil akhir dari penelitian ini didapati suatu ulasan deskriptif kualitatif bahwa pengelolaan dana BOS di SD YPK Ebenhaezer Limalas sudah berjalan sesuai prosedur pelaksanaannya dan bahwa baik pihak sekolah sebagai pengelola BOS, Komite Sekolah 
maupun orang tua/wali murid secara umum maupun secara khusus mereka yang menjadi penerima manfaat telah mengerti dengan baik peran fungsi dan posisi mereka dalam penerapan program pemerintah ini. Peran sinergis ini menghasilkan keberlanjutan peningkatan mutu pendidikan di SD YPK Ebenhaezer Limalas yang teramati oleh peneliti selama masa penelitian ini.

Bahwa pengelola dana BOS pada SD YPK Ebenhaezer Limalas dengan latar belakang bukanlah para sarjana ekonomi, namun dengan pelatihan-pelatihan yang diberikan pihak Dinas Pendidikan maupun instansi keuangan terkait telah meningkatkan kapabilitas pengelola dana BOS untuk mengelola amanat rakyat bagi kepentingan bangsa ini dalam bentuk kinerjanya yang efektif dan efisien.

\section{KESIMPULAN DAN SARAN}

\subsection{KESIMPULAN}

Penetapan RAPBS sebagai bentuk Manajemen Berbasis Sekolah yang terencana dan diarahkan bagi suatu keberlanjutan yang mendukung peningkatan mutu pendidikan di SD YPK Ebenhaezer Limalas telah dilakukan secara musyawarah mufakat dalam rapat kerja sekolah di setiap tahun ajarannya dengan melibatkan pihak sekolah, maupun komite sekolah sebagai representasi dari masyarakat, dan berfungsi sebagai bentuk pemenuhan syarat perolehan dana BOS dan bentuk pengawasan masyarakaat akan pengelolaannya.

1. Pengelolaan dana BOS di SD YPK Ebenhaezer Limalas berjalan dan dilakukan sesuai peraturan yang mengaturnya, diperkuat dengan pelatihan pengelolaan yang diikuti secara rutin dan berhasil guna oleh staf pengelola BOS dan dipertanggungjawaabkaan sesuai prosedur yang berlaku.

2. Pengelolaan dana BOS di SD YPK Ebenhaezer Limalas diawasi secara teknis oleh Dinas Pendidikan Kabupaten Raja Ampat melalui laporan pertanggungjawaaban penggunaan dana BOS oleh pihak sekolah secara berkala sesuai peraturan yang berlaku, dan secara non teknis pengawasan masyarakaat berlangsung dengan baik mengingat masyarakat dalam hal ini warga sekolah adalah pihak yang berhubungan langsung dengan penerapan pengelolahan dana BOS.

\subsection{SARAN}

1. Guna meminimalisir hambatan penerapan kebijakan yang berkaitan dengan pengelolaan BOS, peneliti sarankan agar SD
YPK Ebenhaezer Limalas semakin memfungsikan Komite Sekolah dalam mensosialisasikan program sekolah yang berhubungan dengan BOS.

2. Kepada warga sekolah untuk menyampaikan saran dan kritikan tentang pengelolaan dana BOS secara tertib dan sopan melalui pengadaan kotak saran yang harus dievaluasi oleh sekolah secara berkala dan disampaikan tanggapannya oleh pihak sekolah juga dalam etika yang sama kepada warga dengan melibatkan komite sekolah.

3. Agar dana BOS yang tersalur langsung kepada murid atau orang tua/wali dipergunakan juga sesuai tujuan penyalurannya bagi kepentingan pendidikan anak.

\section{DAFTAR PUSTAKA}

Afifudin, (2012). Pengantar Administrasi Pmbangunan. Konsep, Teori dan Implikasinya di Era Reformasi. Alfabeta, Bandung.

Manullang,M. (2008). Dasar-Dasar Management. Gadjah Mada University Press, Yogyakarta.

Moleong, Lexy J., 2011. Metode Penelitian Kualitatif, PT. Remaja Karya, Bandung

Peraturan Menteri Pendidikan Nasional Nomor 80 Tahun 2016 Tentang Juknis Penggunaan dan Pertanggungjawaban Dana BOS

Siagian, Sondang P. 2007. Administrasi Pembangunan. Konsep, Dimensi dan Strateginya. Bumi Aksara, Jakarta.

Surakhmad, Winarno, 1990. Pengantar Penelitian Dasar Metode Teknik. Tarsito, Bandung.

Terry, George R. (1968), Principle of Management, Saduran Drs. Sujai. Grafika, Bandung.

Thoha, Miftah. 2010. Perilaku Organisasi Konsep Dasar dan Aplikasinya. PT. RajaGrafindo Persada, Jakarta.

Undang-Undang Nomor 20 Tahun 2003 tentang Sistem Pendidikan Nasional

http://cetak.kompas.com/read/2016/29/06/skan dal.dana.bos

http://www.mediaindonesia.com/read/2016/15/ 06/menyoal-penyimpangan-dana-bos 